\title{
The Gender Gap in Subjective Poverty: A Comparative Study
}

\author{
Torild Hammer ${ }^{*}$ and Axel West Pedersen
}

NOVA, Norwegian Social Research, Munthesgate 29, 0260 Oslo, Norway

\begin{abstract}
In this article we use data covering 20 countries from the first round of the European Social Survey (ESS) collected in 2002-2003 to investigate how individual and contextual factors influence the subjective experience of economic strain among married and cohabitating men and women. Our main hypothesis is that countries with low labour force participation among women will tend to feature a gender gap in subjective economic wellbeing in the disfavour of female spouses/partners due to a negative association between labour force participation and economic strain at the individual level. However, we also present a secondary hypothesis about countervailing forces operating at the macrolevel: in countries with a low aggregate labour force participation the economic wellbeing of women could be less dependent on own labour force participation because non-participation is supported by norms of income sharing within the household.

We do find a strong negative association between own labour force participation and the subjective experience of economic strain, particularly among female partners, while we do not find consistent support for our secondary hypothesis about a negative interaction effect with high labour participation at the aggregate level.
\end{abstract}

\section{INTRODUCTION}

A considerable amount of research has been devoted to the question whether women face a higher risk of financial poverty than men and - if so - why [1-5].

In a recent state-of-the-art article on this topic Wiepking and Maas [6] use data from Luxembourg Income Study covering 22 countries to investigate the scope and sources of gender differences in financial poverty between single men and single women. They have chosen to focus on single adult households because the gap in poverty status between males and females living in couples will be zero by definition, as long as poverty is defined in terms of household income. ${ }^{1}$

In their study Wiepking and Maas [6] find that in a majority of the countries covered single females have significantly higher poverty rates than single males, with poverty being defined as having an equivalized household income below $50 \%$ of the median income in each country. However in some countries, including the Scandinavian countries, Ireland and the Netherlands, single men are observed with higher poverty rates than single women. In their attempt to decompose these macro level results, the authors find that gender differences in education explain a significant part of the overall gender gap in poverty, while

\footnotetext{
${ }^{1}$ This does not mean, however, that the level of poverty found among couples is irrelevant for the overall gender gap in poverty between men and women. The overall gender gap in poverty is a function of the interplay between two factors: a) poverty rates among all three family types - single males, single females and couples - and b) the distribution of men and woman across family types. Since more females than males live in single households, and since couples tend to show lower poverty rates than single adults (male or female), the overall poverty rate among woman could very well exceed the rate among men even in countries where single males are poorer than single females.
}

*Address correspondence to this author at the NOVA, Norwegian Social Research, Munthesgate 29, 0260 Oslo, Norway; Tel: +47 225412 00; E-mail: Torild.Hammer@NOVA.no differences in labour market participation appear to be less important. Compositional effects related to differences in educational level explain some of the observed country differences in the gender poverty gap, but country level variables - such as economic growth and a social democratic political tradition - are found to be more important, explaining about a third of the total cross-country variance.

In this article we look at the subjective dimension of a possible gender gap in economic well-being, by investigating the relationship between objective income poverty and the subjective experience of economic strain among men and women in a selection of European countries. Like Wiepking and Maas [6] we attempt to disentangle observed macro-level variations in the gender gap by exploring the impact on both micro-level and macro-level factors on the subjective experience of economic strain. However, in contrast to the strategy adopted by Wiepking and Maas [6], we limit our analysis to men and women living in couples. We do so in order to concentrate attention on possible differences in the way household income poverty impacts on and is felt by male and female partners. Male and female respondents living with a partner represent roughly the same population of households and hence we can assume that objective household conditions are about the same for our male and female respondents. ${ }^{2}$

It is a well established finding in poverty research that the degree of overlap between financial poverty on the one hand and life-style deprivation and subjective poverty measures on the other hand is rather low [7-9]. One potential source of deviation between the traditional objective poverty measures and subjective measures of economic hardship stems from systematic differences in the way household level economic hardship affects male and female partners - both in terms of material consequences and psychological effects.

\footnotetext{
${ }^{2}$ The overlap will not be perfect, however, since married men are typically somewhat older that their female spouses.
} 
Traditional poverty measures have been heavily criticized for treating the family/household as if it were a unitary economic agent with perfect sharing of resources between individual household members [10,11]. According to Pahl, the implicit assumptions about a smooth and harmonious transfer of resources between 'earners' and 'spenders' blurs "the distinctions between controlling, managing, spending and consuming", and ignores any conflict of interest between household members [11]. ${ }^{3}$

Alternatively it seems plausible to assume that variation in the distribution of paid work and the share of total household income brought home by each of the spouses tends to affect power relations within the household with potential consequences for the composition and distribution of household consumption. This has been confirmed in a growing body of research on spending patterns within households. Using data for 102 married couples, Pahl found that while men typically contribute more to the domestic finances than women, women had less control over the couple's finances and a lower personal expenditure than their male partner [11]. However, she also found that the relative disadvantage in terms of control and personal consumption was dependent on women's employment. Women appeared to have more control of money within the household when they were full-time employed. When wives had no earnings, husbands were three times more likely than wives to control the couple's finances.

The presence of children in the household adds a further dimension to the intra-household distribution of income and consumption. Research on low income families with children has repeatedly shown that parents typically give a high priority to spending on their children. However, Middleton et al. [13] found that the priority of spending had the following order: first the children, then the husband and finally the wife. This leads us to expect that poverty among families with children will tend to be more strongly felt by the female partner (either because she is more strongly concerned about potential implications for the children or because she makes the greatest sacrifices).

On the basis of the theory and research just outlined, we hypothesize that women tend to experience higher levels of deprivation and economic strain than their partners/husbands, and that this tendency is conditional upon both micro-level and macro-level factors.

Among micro-level factors we are particularly interested in the role played by the distribution of labour force participation between the spouses. We expect a higher level of economic strain particularly among wives that do not participate in the labour market also when controlling for household poverty status. We further hypothesize that the presence of children will be associated with a higher level of economic strain experienced particularly by women. However, we expect that these relationships may be dependent on contextual factors and here in particular welfare regimes and associated country level differences in female labour force participation.

\footnotetext{
${ }^{3}$ See however Becker [12] for an explicit theoretical exposition of the harmonious model of the family.
}

\section{Welfare Regimes and Hypotheses about Macro-Micro Links}

In recent years much theoretical and empirical work has been done on the relationship between welfare regime characteristics and female labour force participation [5,14-18]. Jane Lewis [14-16] has suggested a classification of national welfare regimes in terms of the way they structure the relationship between paid work and unpaid work and in particular whether they support traditional male-breadwinner household forms and whether they treat women primarily as mothers or workers.

In different versions of this comparative classification the Scandinavian countries are typically identified as belonging to a category encouraging male and female breadwinning, through generous leave schemes, individualised tax and benefit systems and the provision of public services, in particular the provision of state-subsidised childcare. In contrast Germany and southern European countries are classified as male breadwinner regimes because access to welfare is strongly linked to labour market participation while simultaneously encouraging family dependence. This means that the risks covered by the welfare state are mainly male risks and women's entitlements within the system are primarily derived from their husbands.

In a comparative analysis of the impact of female employment activity in nineteen developed countries, Daly [18] suggests that the country cases can be grouped into three models according to observed variation in the ratio between male and female employment rates, caring policies for children and the elderly, and the tax treatment of married couples (individual versus joint taxation). The first model was found in the Scandinavia countries, classified as typical dual breadwinner societies. The second model was found in Continental Euopean countries with an average female employment rate about $60 \%$. The third model was characterised by a privatized system of family care. This is a pattern typifying both the Mediterranean countries and the liberal welfare states along with Ireland. In these male breadwinner countries female employment rates are very low, especially among mothers. The exception is Portugal, with a very high female employment rate and low level of public support for working mothers. Daly concludes that female employment rates can not directly be read off as a function of family welfare policies. However, we will argue that female employment rates of different countries will function as a crude measure of family welfare policies differentiating the Scandinavian, Continental and Mediterranean welfare regimes [18].

It is straightforward to hypothesize the existence of a lower level of subjective economic wellbeing among women living in countries that belong to the male breadwinner regime-group, primarily through an indirect compositional effect of variation in female labour force participation: Female labour force participation tends to be higher in dual breadwinner than in male breadwinner regimes and this is in turn is expected to boost the aggregate level of subjective economic wellbeing of women through the micro-level mechanisms discussed above.

However, we will not a priori exclude a possible counterhypothesis holding that the expected positive effect of labour force participation by the female spouse and a balanced 


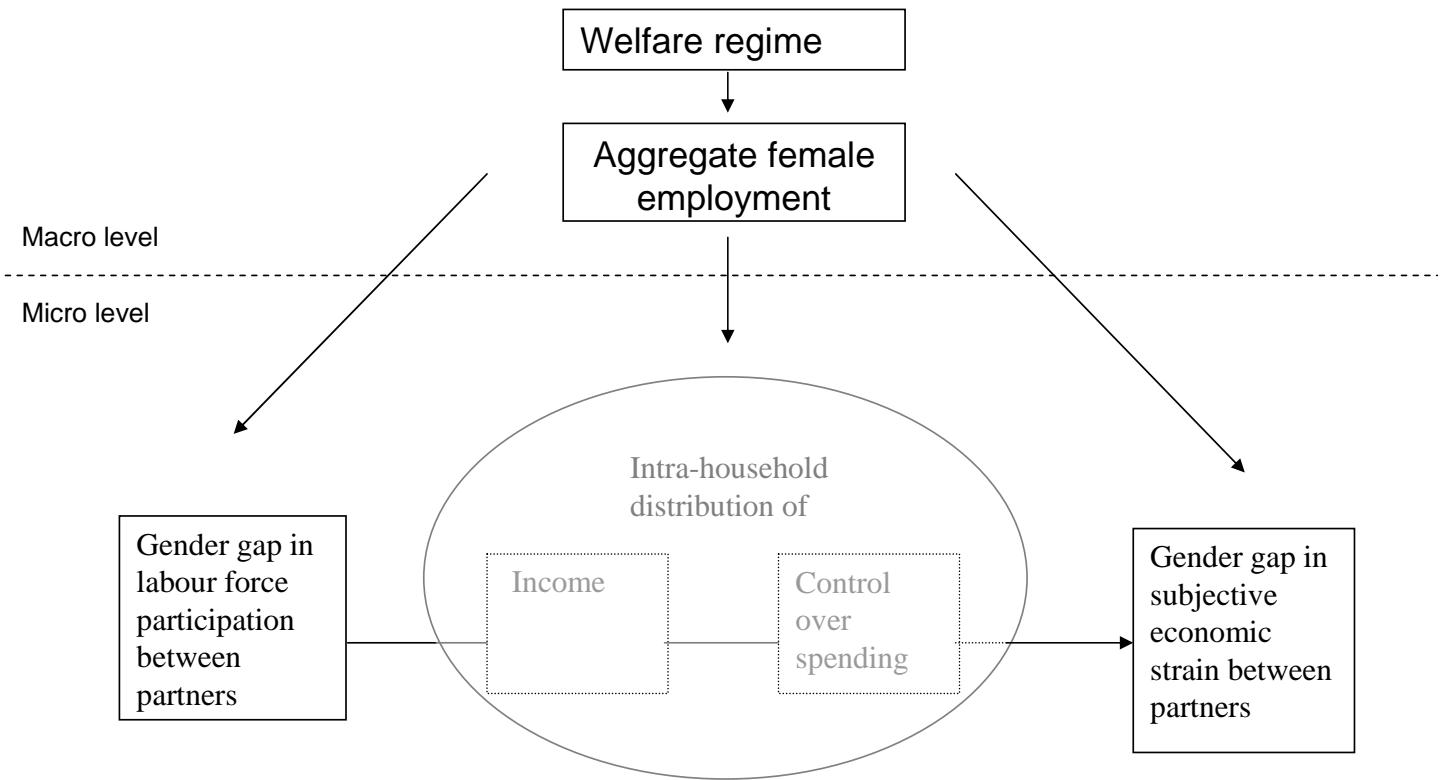

Fig. (1). Theoretical model.

control of family income could be socially and institutionally contingent. One could imagine, for instance, that the economic wellbeing of women in dual breadwinner societies is more strongly dependent on their own actual participation in the labour market - i.e., adherence to the dual breadwinner norm -, and correspondingly less dependent on own labour force participation in male breadwinner regimes where non-participation is more common and supported by norms of income sharing within the household.

Fig. (1) gives a graphical summary of the main causal links implied by our theoretical model. At the individual level we assume that a wide gender gap in labour force participation between spouses will result in a gender gap in subjective economic strain, and vice versa. Labour force participation by the female spouse leads to a more balanced control of money within the household that in turns implies more female control of spending and, therefore, a smaller gender gap in subjective economic strain. Our assumptions about the possible influence of welfare state regimes are indicated by three arrows: an indirect effect via aggregate variation in female employment, a direct effect on gender differences in experienced economic hardship, and finally the third arrow is included to indicate possible interaction effects between welfare regime and the micro level relationships.

In the empirical analysis we do not attempt to open the black-box of within household distribution of economic resources. The reason is limitations in the available data that we shall explain below. Hence, we pass over the two intermediate links - the distribution of money income and control over spending - in the stipulated causal chain from female labour force participation to gender differences in the subjective experience of economic hardship. On the other hand, our empirical analyses include a wider set of independent variables and explore interaction effects that are not explicitly shown in the graph. Education is included partly to serve as a proxy for individual income that we unfortunately do not observe, and the presence of children is included to test the propositions set out above about gender differences in the sensitivity to the needs of children.

\section{Data and Methods}

We have used data from the European Social Survey, Round 1, covering 20 countries.

The data were collected in 2002-2003 by personal interviews. The overall response rate is about $60 \%$ with considerable variation across countries ranging from $34 \%$ in Switzerland to $70 \%$ in Sweden. As already mentioned we have used data on cohabitating or married couples $(\mathrm{N}=26818)$, and the data has been weighted by the so-called design weights in all analyses [19].

\section{The Dependent Variable}

Our dependent variables - subjective poverty and economic strain - are derived from a question about the respondent's feelings about the household's income situation. After a question about the actual level of the household's current income (measuring the objective income situation), respondents were asked: "How do you feel about the household's income nowadays?", followed by four alternative response categories: 1) "Living comfortably on present income", 2) "Coping on present income", 3) "Finding it difficult on present income", and 4) "Finding it very difficult on present income". In the following we say that respondents are in "subjective poverty" if they have chosen one of the two last response categories, and a variable measuring the full variation over the four response categories is called "subjective economic strain" (or alternatively "subjective economic wellbeing").

We should be careful to note that respondents were asked to evaluate their household's income. Hence, we do not directly measure subjective poverty in terms of individual command over resources. We investigate gender differences in the evaluation of household income, assuming that variation in 
household income has a differential effect on males and females, depending on the sharing of paid work within the family. In other words, we believe that an unbalanced sharing of household resources is likely to manifest itself in a systematic gender gap in the subjective evaluation of a certain level of household income.

\section{The Unit of Analysis}

In the lower, micro-level part of our theoretical model (Fig. 1) we talk about a gender gap in the distribution of paid work within the family and a gender gap in subjective poverty and subjective economic strain. Unfortunately our data do not allow us to use the couple as the primary unit of analysis as this formulation ideally would require. The sampling unit in ESS is individuals, and we only know about other household members through questions asked to the individual respondent. Hence, we are unable to compare the level of subjective economic strain between spouses and use this as the main dependent variable. What we can do instead is to compare subjective poverty and subjective economic strain between cohabitating males and females drawn from roughly the same population of couples. The dependent variable is subjective poverty and subjective economic strain while a possible gender gap is captured by adding a gender variable and various interaction terms between gender and relevant explanatory variables in the multivariate analyses.

\section{Independent Variables}

In the multivariate analyses below we use a range of micro-level variables. Most importantly we need to control for the household's objective poverty status. In the questionnaire respondents are asked to report their current household income in EURO in pre-categorised intervals. On the basis of this rather crude income measurement we have computed an equivalized household income for each respondent using the so-called modified OECD-scale. A household is classified as poor if its equivalized income is below 50 percent of the national median income (estimates derived from the data-set). Other micro-level variables will be introduced along with the presentation of results.

As suggested in the theoretical sections we also introduce macro-level variables to the analysis. The range of potentially relevant variables is wide, but due to the limited number of macro-level units (20 countries) available, we have chosen to only include variables measuring the aggregate level of female labour force participation. These variables have been obtained from OECD statistics and added to the dataset [20].

\section{Statistical Modelling}

We start the presentation of results by looking at variation in subjective poverty rates across the twenty country samples. In order to investigate our hypotheses about the sources of variation in subjective economic wellbeing we move on to apply a range of multivariate statistical models. Given the nested nature of the data and the hierarchical aspects of our theoretical model we estimate different multilevel models that are available in the statistical package, SPSS.

\section{Descriptive Results - Cross-National Variation in the Gender Gap}

We start our presentation of results by looking at aggregate levels of subjective economic deprivation among cohabitating males and females in our sample of 20 European countries. The lines in Fig. (2) show the share of male and female respondents who can be classified as subjectively poor, i.e. they report that their present household income is difficult or extremely difficult to live on.

The most striking feature of the diagram is the vast crossnational differences in the prevalence of subjective economic strain. In countries like Greece, France Poland and Hungary between 40 and 50 percent of both males and females report to live in subjective poverty, while subjective poverty rates are below 10 percent in the Scandinavian countries as well as in the Netherlands and Switzerland. The ranking of countries in

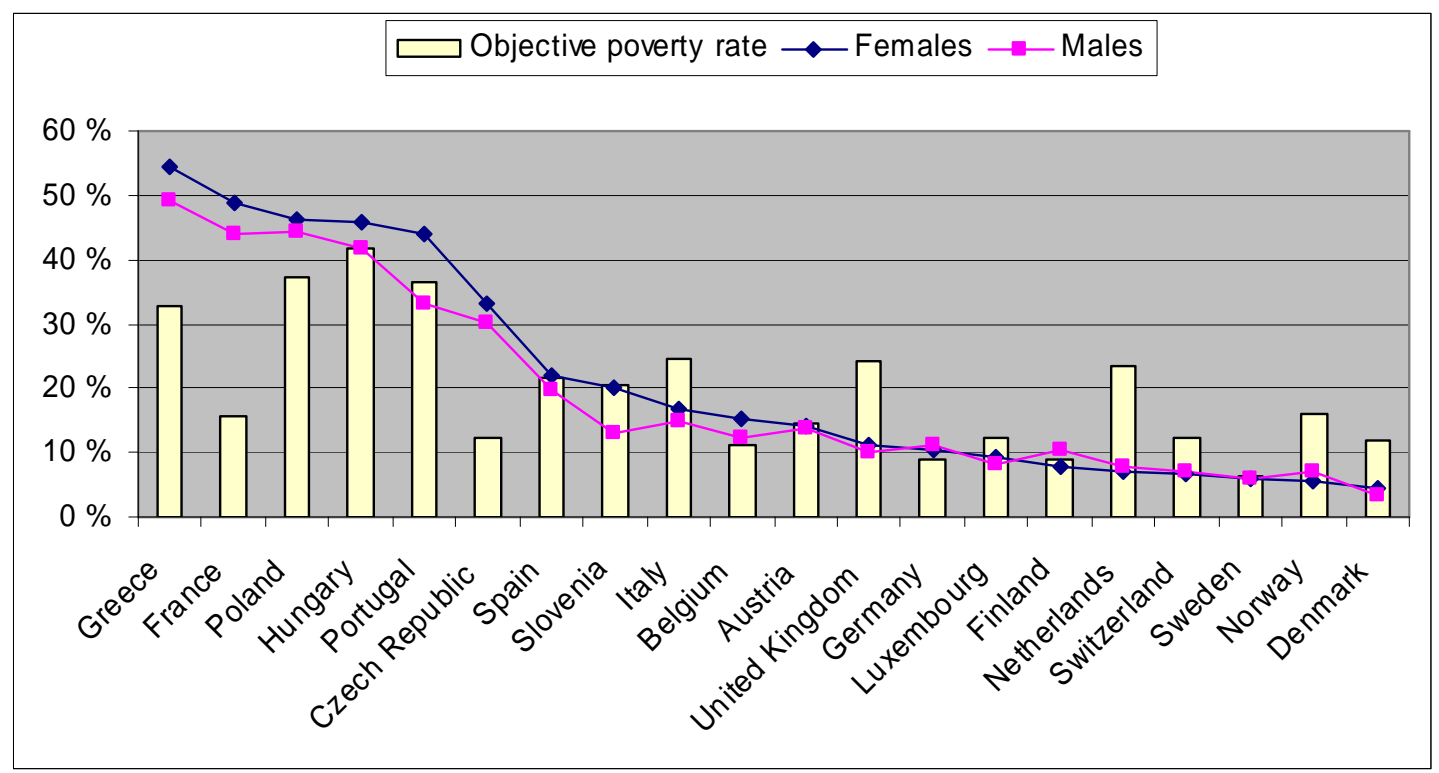

Fig. (2). The prevalence of subjective poverty among cohabitating men and women (lines) and objective poverty rates (columns) in European countries. 


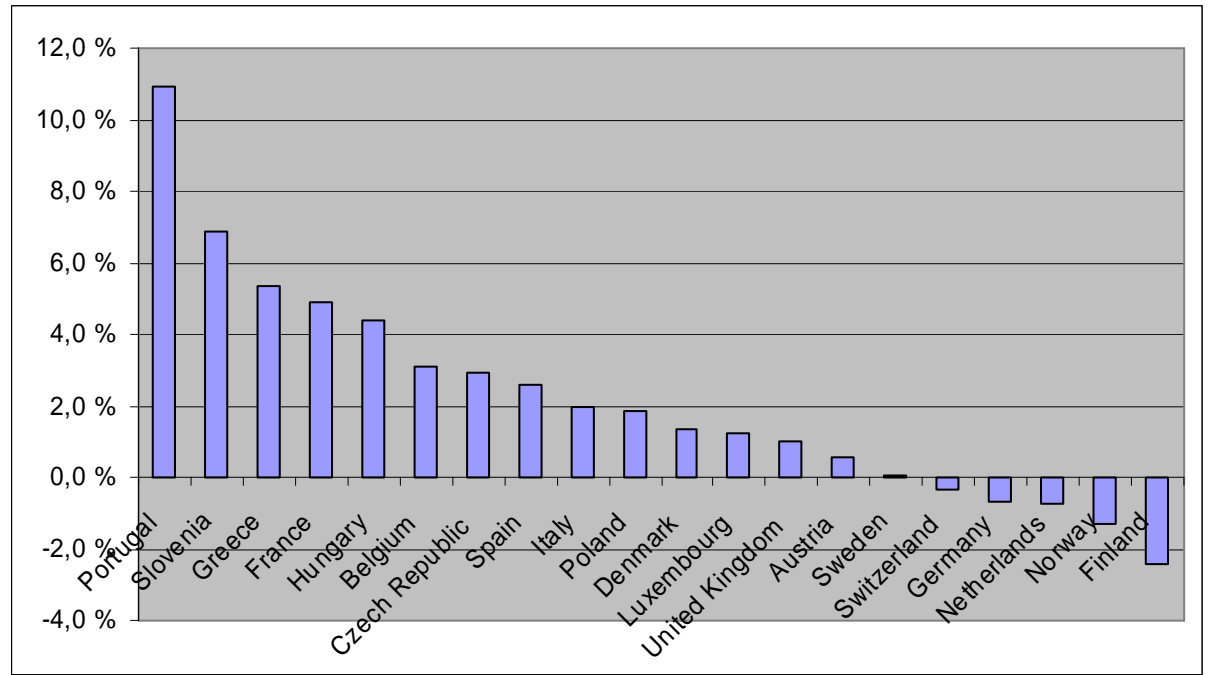

Fig. (3). The gender gap in subjective poverty rates. Difference in percentage points between males and females in each country.

terms of subjective poverty is less than perfectly correlated with our corresponding estimates of objective poverty rates shown as columns in Fig. (2). It is interesting to note that some of the poorer Southern and Eastern European countries show very high rates of subjective economic strain compared to their estimated objective poverty rate, while the pattern is reversed for some of the more affluent Northern European countries. This might be an indication that the subjective experience of economic strain among Europeans is sensitive to variation in absolute income levels and not only to the relative income position within each country as assumed by conventional poverty measures.

Even though the objective household income situation should be roughly similar between married and cohabitating males and females in each country, there are differences in the level of subjective economic strain reported by the two genders - typically in the disfavour of women. In the entire pooled sample 22.5 percent of the female respondents report to be subjectively poor compared to 19.4 percent among the male respondents. While the overall gender gap for the entire sample is rather modest at approximately 3 percentage points, some countries show significantly higher levels of subjective poverty among women as compared to men.

The absolute differences in subjective poverty rates are shown for each country in Fig. (3). The gender gap is highest in Portugal with 11 percentage points followed by Slovenia (just below 7), Greece and France (around 5). Five of the twenty countries show slightly negative gender gaps in the sense that subjective poverty is higher among males. In Finland where this tendency is strongest, the difference in disfavour of male respondents is just above 2 percentage points.

As we have seen, the overlap between our indicators of objective and subjective poverty is less than perfect at the macro level. Fig. (4) shows the degree of overlap found at

\footnotetext{
${ }^{4}$ When calculating this overall mean difference, the data have not been weighted to take account of differences in population sizes between countries.
}

the individual level for the entire pooled sample. As one might expect, objective poverty status is not a perfect predictor of subjective poverty at the individual level either, but the share experiencing economic strain is of course very much higher among respondents with incomes below the objective income poverty line than among the non-poor sections of the population. For the sample as a whole the share reporting to be in subjective poverty is close to 50 percent among those with incomes below the poverty line, while only 15 percent of the sample with incomes above the respective national poverty line report to be in subjective poverty.

\section{Analytical Results - Multivariate Analyses}

We will now turn to a set of multivariate analyses attempting to explain the observed variation in subjective economic strain. Table 1 shows the impact of employment upon deprivation among men and women controlling for poverty using a multilevel model including the impact of female full time labour market participation in each country.

Table 1. Results from Multilevel Analysis. Dependent Variable: Subjective Economic Strain. Married and Cohabitating Individuals ( $=22357$ ). Mixed Model Weighted Estimates

\begin{tabular}{|c|c|c|c|c|}
\hline Parameter & Estimate & Std.Error & $\mathbf{T}$ & Sig. \\
\hline \hline Intercept & 1.45 & .25 & 5.78 & .001 \\
\hline 1=Woman & .03 & .01 & 2.0 & .05 \\
\hline Wrkhtot & -.002 & .0002 & -8.33 & .001 \\
\hline Woman*wrkhtot & -.001 & .0004 & -2.29 & .01 \\
\hline Poor=1 & .60 & .011 & 50.14 & .001 \\
\hline Women work & .009 & .005 & 1.71 & .10 \\
\hline
\end{tabular}

\begin{tabular}{|c|c|c|}
\hline Parameter & Estimate & Std.Error \\
\hline \hline Residual & .45 & .04 \\
\hline Intercept variance & .123 & .38 \\
\hline
\end{tabular}




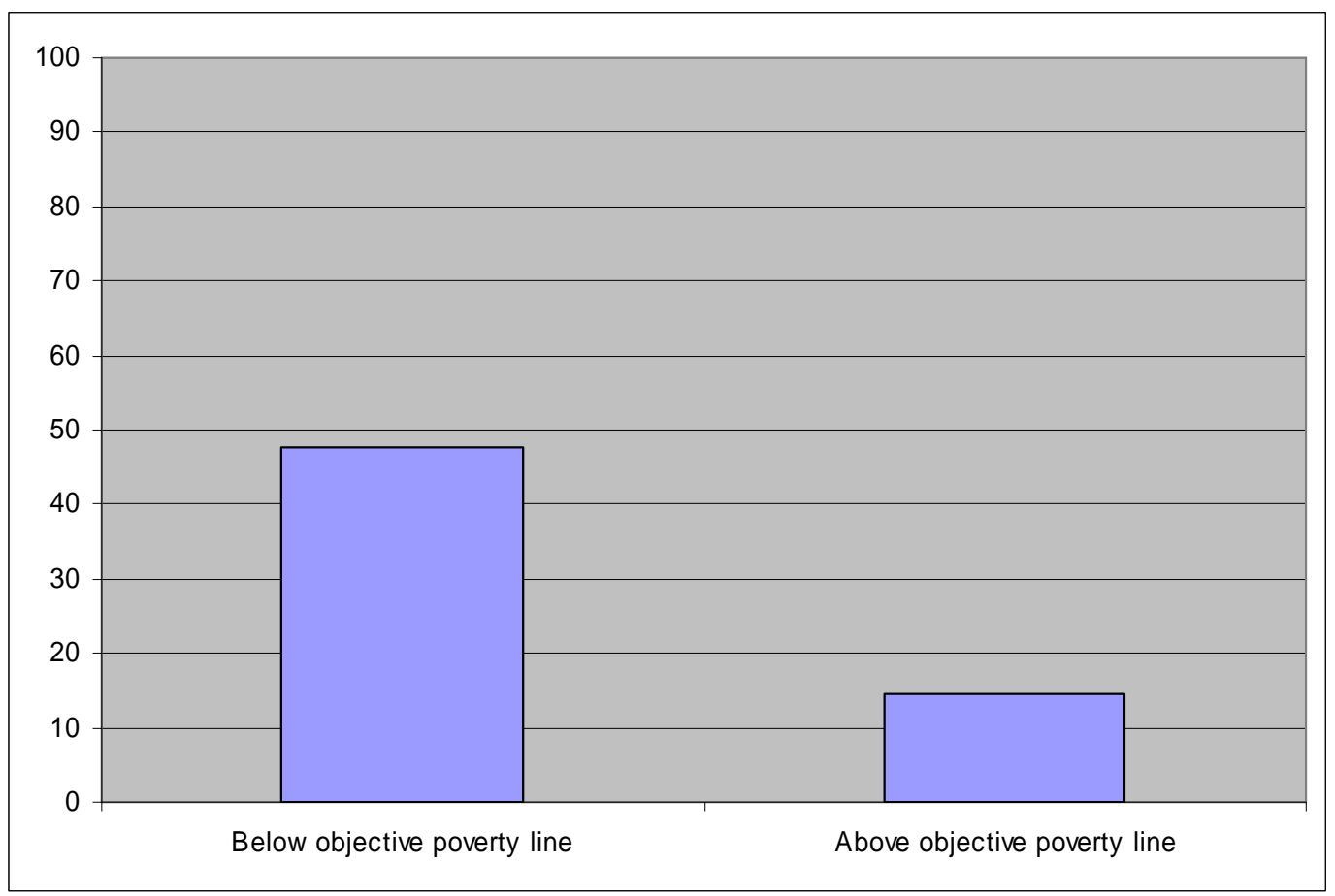

Fig. (4). Subjective poverty rates among poor and non-poor respondents. Pooled sample.

The results confirm some of our initial hypotheses. First of all, we see that the objective poverty status of the household has a strong effect on subjective economic strain as one would expect. Secondly - and more important in our context - women report higher levels of economic strain than men, when controlling for the other variables in the model, including the household's objective poverty status. This baseline gender effect is statistically significant, but rather modest in substantive terms. Thirdly both male and female respondents turn out to be less dissatisfied with their household income if and to the extent they work themselves (Wrkhtot). More interestingly and still in accordance with expectations, we find a negative coefficient for the interaction between genders (female) and working hours, implying that the negative effect of the respondent's participation in paid work on economic strain is stronger for females than for males. Put in positive terms, the results indicate that the subjective economic wellbeing of female partners is significantly enhanced by their own active labour force participation.

Finally we have in this model included a macro-level variable (Women work) measuring the proportion of females working full time in each respective country. This variable is found to have a small positive effect on subjective economic strain for both males and females taken together, although the coefficient fails to reach statistical significance at the conventional 5 percent level. When interpreting this finding one should remember that we have already controlled for the respondent's own work attachment. A positive coefficient for this aggregate level variable would imply that in countries where many women work full time, respondents tend to be less satisfied with their own household income - given a certain level of their own work participation (and poverty status). This could be seen as - albeit weak - confirmation of our hypothesis that individual economic satisfaction is more contingent on own labour force participation and control over personal income in countries where female labour force participation has become the dominant norm. Below we shall explore this further in a separate analysis among female respondents.

Table 2. Results from Multilevel Analysis. Dependent Variable: Subjective Economic Strain. Married and Cohabitating Individuals $(\mathrm{N}=\mathbf{2 1 8 0 0})$. Mixed Model Weighted Estimates

\begin{tabular}{|c|c|c|c|c|}
\hline Parameter & Estimate & Std. Error & $\mathbf{T}$ & Sig. \\
\hline \hline Intercept & -5.55 & 1.6 & -3.45 & .001 \\
\hline Woman=1 & .11 & .04 & 2.76 & .01 \\
\hline Wrkhtot & -.003 & .0004 & -7.69 & .001 \\
\hline Age & -.005 & -.0007 & -6.4 & .001 \\
\hline Education & -.102 & .006 & -16.00 & .001 \\
\hline Citizenship & -.19 & .05 & -3.66 & .001 \\
\hline Children home & .14 & .02 & 6.96 & .001 \\
\hline Unemployed & .15 & .02 & 7.50 & .001 \\
\hline Work partner & -.09 & .02 & -3.6 & .001 \\
\hline Poor=1 & .45 & .03 & 18.04 & .001 \\
\hline Work partn*gender & -.15 & .04 & -3.25 & .001 \\
\hline Female employment & -.02 & .01 & -1.91 & .07 \\
\hline
\end{tabular}

\begin{tabular}{|c|c|c|}
\hline Paramenter & Estimate & Std. Error \\
\hline \hline Residual & .37 & .007 \\
\hline Intercept variance & .11 & .04 \\
\hline
\end{tabular}


The next question is whether these effects remain significant controlling for other factors that may influence subjective economic satisfaction, such as educational level, unemployment, and the presence of children in the household. In the model presented in Table $\mathbf{2}$ we have also included information about whether the respondent's partner is working, and the respondent's age, working hours and citizenship (whether the person is born in the country).

As before, objective poverty status is a strong predictor of subjective economic strain. In addition to that, most of the individual level variables included in this model have significant effects in the expected direction. Subjective economic strain becomes lower with increasing working hours of the individual, age, educational level and if the spouse is working ('Work partner'), and it is higher for non-citizens, for unemployed and for families with children ('Children home'),

For all these individual level variables we have tested out if there is a significant interaction effect with gender. However in the model presented here we decided to only keep interaction effects that are significant at the 5 percent level (modelling results with the full set of interactions can be obtained from the authors upon request).

So what does the table tell about the gender gap? First and foremost we find that women report somewhat higher levels of subjective strain than men, also after controlling for this broader set of individual level variables. However, contrary to our initial expectations only one of the gender interactions turned out significant, namely the interaction with a working spouse. The results here indicate that having a working spouse is even more important for the subjective economic wellbeing of women than it is for men. The lack of a significant interaction with own work participation (similar to the one appearing in Table $\mathbf{1}$, suggests that working yourself is equally important for men and women. This pattern is somewhat at odds with our initial expectations but not at all implausible.

Contrary to our initial expectations and to earlier findings reported in the literature we do not find that the subjective economic wellbeing of women is more sensitive to the presence of children as compared to men.

Finally, the coefficient for our macro-level variable this time measuring overall female labour force participation (Female employment) - now comes with a positive sign, indicating that the experience of economic strain decreases for both men and women with the aggregate level of female labour force participation. Although we should hasted to add that the coefficient fails to reach significance at the 5 percent level, the finding is contrary to our initial hypothesis that any positive effect of high female labour force participation would work through individual level participation - leaving a negative contextual effect due to social expectations. One could speculate that the weak positive association found here might be driven by other features of welfare regimes that are conducive to female labour force participation. Unfortunately, our possibilities to identify alternative causal factors at the macro level are severely limited due to the small number of country cases.
In Table $\mathbf{3}$ we show the results of an ordinary linear regression model with the same individual level variables as in Table 2 but with the macro-context represented by country dummies.

Table 3. Results from OLS-Regression Model with Country Dummies. Dependent Variable: Subjective Economic Strain. Married and Cohabitating Individuals, $(\mathbf{N}=$ 21800)

\begin{tabular}{|c|c|c|c|c|}
\hline & B & Beta & $\mathbf{T}$ & Sig. \\
\hline Constant & -6.62 & & 4.46 & 0.001 \\
\hline Poor & .44 & 0.19 & 16.8 & 0.001 \\
\hline Women=1 & .12 & 0.07 & 2.9 & 0.01 \\
\hline Yearborn & .005 & 0.08 & 6.06 & 0.001 \\
\hline Education & -.10 & -0.18 & -14.66 & 0.001 \\
\hline Citizenship & -.16 & -0.03 & -2.8 & 0.01 \\
\hline Children home & .15 & 0.09 & 7.36 & 0.001 \\
\hline Wrk partn & -.09 & -0.05 & -3.7 & 0.001 \\
\hline Wrkpart*gend & -.15 & -0.08 & -3.28 & 0.001 \\
\hline Wrk hours & -.003 & -0.10 & -7.71 & 0.001 \\
\hline \multicolumn{5}{|l|}{ Country dummies*: } \\
\hline Austria & -.23 & -0.02 & -1.8 & 0.07 \\
\hline Belgium & -.33 & -0.06 & -5.7 & 0.001 \\
\hline Sweden & -.43 & -0.07 & -6.2 & 0.001 \\
\hline Greece & .43 & 0.04 & 3.8 & 0.001 \\
\hline Denmark & -.57 & -0.27 & -16.9 & 0.001 \\
\hline Spain & -.12 & -0.02 & -1.7 & 0.07 \\
\hline Switzerland & -.49 & -0.14 & -11.2 & 0.001 \\
\hline Czechoslovakia & .44 & 0.06 & 5.4 & 0.001 \\
\hline Finland & -.26 & -0.02 & -1.7 & 0.08 \\
\hline France & -.47 & -0.22 & -13.6 & 0.001 \\
\hline UK & -.34 & -0.07 & -5.94 & 0.001 \\
\hline Italy & -.44 & -0.03 & -1.94 & 0.05 \\
\hline Luxemburg & -.60 & -0.07 & -5.93 & 0.001 \\
\hline Netherlands & -.48 & -0.17 & -12.2 & 0.001 \\
\hline Norway & -.41 & -0.12 & -9.4 & 0.001 \\
\hline Poland & .30 & 0.08 & 6.23 & 0.001 \\
\hline Portugal & .14 & 0.02 & 1.77 & 0.07 \\
\hline Slovenia & -.14 & -0.03 & -2.79 & 0.01 \\
\hline Hungary & .25 & 0.07 & 5.3 & 0.001 \\
\hline $\begin{array}{l}\text { Adjusted R Square with } \\
\text { country dummies }\end{array}$ & .44 & & & \\
\hline
\end{tabular}

*Ref: Germany

The pattern of coefficients for the individual level variables is basically the same as in Table 2 . While these variables alone explain 22 percent of the total individual level variance (results not shown here), the entire model with country dummies 
accounts for 44 percent of the total variation in perceived economic strain.

Finally we have estimated a multilevel model for the sub-sample of women in order to explore in more detail the factors that appear to influence perceived economic strain among female partners. The model contains the same set of individual level variables as in the previous joint analyses. In addition we have included education that might partly function as a proxy for (potential) individual income. The results are presented in Table 4.

As mentioned in the introduction, Wiepking and Maas [6] found a strong effect of education on single women's objective poverty rate. Similarly we find a very strong effect of education on married and cohabitating women's subjective economic wellbeing (i.e. a negative effect on perceived financial strain).

Furthermore, in this separate analysis of the female sub-sample we find - for the first time - a statistically significant positive effect of aggregate female labour force participation on economic wellbeing (a negative effect on economic strain). This result is once again contrary to our hypothesis about a negative aggregation effect and it is further indication that there is something about countries with high female labour force participation that is conducive to the economic wellbeing of women - over and above the positive individual effect of having an individual income through work. However, we find a statistically significant interaction effect here between the effect of own education and aggregate female labour force participation; i.e., the positive effect of own education appears to be strongest in countries with a comparatively low level of female labour force participation. Again this is

Table 4. Mixed Model. Dependent Variable Subjective Economic Strain. Women. Weighted Estimates $(\mathrm{N}=\mathbf{1 0 2 8 0})$

\begin{tabular}{|c|c|c|c|c|}
\hline Parameter & Estimate & Std. Error & $\mathbf{T}$ & Sig. \\
\hline \hline Intercept & -8.3039143 & 1.3568963 & -6.120 & .000 \\
\hline Wkhtot & -.0021750 & .0003435 & -6.331 & .000 \\
\hline Yearborn & .0064668 & .0005880 & 10.999 & .000 \\
\hline Education & -.3102366 & .0436006 & -7.115 & .000 \\
\hline Citizenship & -.2233637 & .0339475 & -6.580 & .000 \\
\hline Children home & .1043115 & .0147166 & 7.088 & .000 \\
\hline Unemployed & .1586201 & .0147717 & 10.738 & .000 \\
\hline Work partner & -.1946445 & .0177388 & -10.973 & .000 \\
\hline Poor & .4410062 & .0169112 & 26.078 & .000 \\
\hline Womwork & -.0271224 & .0104077 & -2.606 & .016 \\
\hline $\begin{array}{c}\text { Educational level* } \\
\text { wom work }\end{array}$ & .0030119 & .0006130 & 4.914 & .001 \\
\hline
\end{tabular}

\begin{tabular}{|c|c|c|}
\hline Parameter & Estimate & Std. Error \\
\hline \hline Residual & .4288073 & .0057884 \\
Intercept variance & .1196332 & .0382021 \\
\hline
\end{tabular}

somewhat contrary to our expectation about an aggregation effect: that subjective economic wellbeing is more contingent on own (potential) labour force participation in countries where most women do have a labour market career.

\section{CONCLUSIONS}

In this article we have investigated gender differences in subjective poverty and subjective economic wellbeing among married and cohabitating males and females. As expected we do find a higher level of subjective poverty among women than men in most countries. However, in Germany, Finland, Norway and Switzerland men show slightly higher subjective poverty rates than women. Interestingly, the pattern of crosscountry variation in subjective poverty gaps closely resembles the pattern of cross-country variation in objective poverty gaps between single males and females found by Wiepking and Mass [6], with higher poverty rates among single men than single women in Scandinavia, Germany and Ireland.

In our sample of married and cohabitating individuals, the observed gender gap in subjective poverty cannot be driven by differences in household characteristics. It must be the result of gendered social and psychological processes that mediate the connection between objective household characteristics and subjective economic wellbeing. Our main hypothesis is that the unequal distribution of labour force participation among spouses is a key mechanism behind the gender gap in subjective poverty.

In accordance with our hypotheses we find that the respondent's own employment status is an important factor explaining variation in subjective economic wellbeing - also when household poverty status is kept constant. In the first of our multivariate models we even find that the positive effect of own labour force participation is stronger for women than for men in reducing subjective income deprivation. These results are in accordance with theories developed by Pahl [10,11] among others, holding that women in employment have better economic control of resources in the family and hence experience less income deprivation if they are in employment and earn their own income. Individual-level variation in female labour force participation explains a significant share of the observed variation in gender gaps in subjective poverty among the European countries.

In a more comprehensive model, however, we find that the partner's employment status is important too, and in fact more important for women than for men. The most likely explanation is that men have higher (potential) wages than women, and therefore are able to contribute more to the income of the household.

When individual level variation in labour force participation is controlled for, we do not find strong and consistent effects of the aggregate level of female labour force participation on subjective economic wellbeing among women; i.e. we do not find support for the supposition that being outside the labour market is more detrimental to subjective economic wellbeing in countries where the dual breadwinner family is the established norm. The weak contextual effects that we do find tend to go in the opposite direction: the baseline level of subjective wellbeing is higher in dual breadwinner societies. A possible explanation is that most countries featuring high female labour force participation 
are developed welfare states with generous benefits and a developed social security system, as discussed in the introduction, with Portugal as a notable exception. In other words, a comprehensive welfare state may operate as a buffer against deprivation among women independent of their employment activity.

Moreover, we do not find support for the hypothesis that women are more sensitive than men to economic strain in families with children. Our results show that to have children increased subjective deprivation equally among men and women.

Wiepking and Maas [6] found in their study that educational level explained more of the gender gap in poverty than labour market activity. Similarly, we find a strong impact of educational level on married and cohabitating women's perceived economic strain also when controlling for labour market participation. The explanation may be that higher education among women leads to greater control over economic resources within the family even if they are not in employment and have their own income. We also find that the impact of educational level in reducing income deprivation is stronger among women in male breadwinner societies than in dual breadwinner societies. In other words: the positive effect education is stronger in societies where women are less likely to have an income of their own, and where nonparticipation is more common and supported by norms of income sharing within the household. The results may imply that even if women in male breadwinner societies do not have an income from employment, potential income may have an important influence on the distribution of control over realised financial resources within the family.

Finally we should once again stress a severe limitation of the present study that follows from the fact that we do not have data on matched pairs of spouses and lack any information about control and spending within the family between husband and wife. To really untangle the "black box" of intra-household distribution and its effect on the economic wellbeing of male and female spouse's one would need in-depth household level interviews. To bring about and analyse such data in a comparative context should be an important challenge for future research.

\section{ACKNOWLEDGEMENTS}

We would like to thank four anonymous referees for helpful comments and suggestions to this paper.
The data, European Social Survey (ESS) 2004/2005 has been made available through the Norwegian Social Science Data Services (NSD) as the data archive and distributor of the ESS data. The Central Co-ordinating team (CCT) of ESS and the producers bear no responsibility for the uses of the ESS data, or for interpretations or inferences based on these uses.

\section{REFERENCES}

[1] Pearce D. The feminization of poverty: women, work and welfare. Urban Soc Change Rev 1978; 11: 28-36.

[2] Goldberg GS, Kremen E. The feminization of poverty: only in America? Westport: Greenwood Publishing Group. 1990.

[3] Casper LM, McLanahan SS, Garfingel I. The gender-poverty gap: what can we learn from other countries. Am Sociol Rev 1994; 59: 594-605.

[4] Wright RE. Women and poverty in industrialized countries. J Income Distrib 1995; 5: 31-46.

[5] Daly M. The gender division of welfare. The impact of the British and German welfare states. Cambridge: Cambridge University Press 2000

[6] Wiepking P, Maas I. Gender differences in poverty: A cross national study. Eur Sociol Rev 2005; 21(3): 187-200.

[7] Whelan CT, Layte R, Maitre B. Multiple deprivation and persistent poverty in the European Union. J Eur Soc Policy 2002; 12(2): 91-106.

[8] Whelan CT, Layte R, Maitre B. Persistent income poverty and deprivation in the European Union; An analysis of the first three waves of the European Community Household Panel. J Soc Policy 2003; 32(1): 1-18.

[9] Kangas O, Ritakallio V-M. Different methods. Different trends poverty in Finland in the 1990s. Publications of the Department of Social Policy, University of Turku 2005.

[10] Pahl J. Household spending, personal spending and the control of money in marriage. Sociology 1990; 24(1): 19-138.

[11] Pahl J. His money, her money: Recent research on financial organisation in marriage. J Econ Psychol 1995; 16(3): 361-76.

[12] Becker Gary. A treatise on the family. Cambridge: Cambridge University Press 1981.

[13] Middleton S, Ashworth K, Braithwaite I. Small fortunes. Spending on children, childhood poverty and parental sacrifice. York: Joseph Rowntree Foundation 1997.

[14] Lewis J. Gender and the development of welfare regimes. J Eur Soc Policy 1992; 2(3): 159-73.

[15] Lewis J. Gender and welfare regimes: Further thoughts social politics. Gender Welfare Regimes 1997; 4(2): 160-77.

[16] Lewis J. Gender and welfare state change. Eur Soc 2002; 4(4): 33157.

[17] Esping-Andersen G. Social foundations of postindustrial economies. Oxford: Oxford University Press 1999.

[18] Daly M. A fine balance: Women's labour market participation in international comparison. In: Scharpf FW, Schmidt VA, Eds. Welfare and work in the open economy, Diverse responses to common challenges. Oxford: Oxford University Press 2002; vol. 2, pp. 467510 .

[19] Jowell R. The Central Co-ordinating Team European Social Survey 2004/2005. Technical Report. London: Centre for Comparative Social Surveys, City University 2005.

[20] OECD. OECD employment outlook 2005. Paris: Organization for Economic Co- operation and Development 2005. 